\title{
Boost converter system modelling and incremental conductance algorithm for photovoltaic system via Matlab/Simulink
}

\author{
Benlafkih Abdessamad and Chafik Elidrissi Mohamed \\ ab.benlafkih@gmail.com, labogem15@gmail.com \\ Laboratory of Engineering Energy and Materials, Faculty of Sciences \\ University Ibn Tofail, Kenitra, Morocco
}

\begin{abstract}
This paper presents a method of modeling and simulation of photovoltaic panel in MATLAB/Simulink using solar cell block from SimElectronics library. The method is used to determine the characteristic of a particular photovoltaic cell panel I-V \& P-V, and to study the influence of different values of solar radiation at different temperatures concerning performance of photovoltaic cells and to study the influence of different values of temperatures at different solar radiation. Also from the simulation it is inferred how the maximum power point is tracked using Incremental conductance algorithm to maximize the power output of the PV panel.
\end{abstract}

Keywords: System modeling, solar cell, MPPT, photovoltaic panel, boost converter, Incremental conductance algorithm, simulation, Matlab/Simulink.

\section{Introduction}

Renewable energy sources offer clean production of electrical power using sunlight, wind, biomass, tidal waves etc. Renewable energy generation have grown greatly due to the concerns of climate change and the increase in oil prices. The growth in renewable energy has been very consistent in the last two decades. Not only the increasing concerns regarding climate change and the soaring of oil prices but also the great support by renewable energy legislation and incentives with a close to 150 billion US Dollars in 2007 have brought this alternative source of electrical power generation to the big picture [1]. Photovoltaic (PV) systems are one of the most popular renewable energy sources. It is an interesting energy source as it is not only renewable but also inexhaustible and non-polluting unlike the conventional fossil fuels such as coal, oil and gas. These unique features have made power generation through Photovoltaic sources one of the most popular renewable energy sources in last decade [2]. Photovoltaics convert sunlight into electrical energy using photoelectric effect. Sun's radiation is converted directly into usable electricity by the photovoltaic systems. Photovoltaic (PV) systems are made of photovoltaic modules which are semiconductor devices that convert the incident solar radiation directly into electrical energy. PV power depends greatly on solar irradiation and temperature. As a result the power generated by solar systems are not constant. Apart from this clean conversion of solar energy into electrical energy, one thing which is holding back the photovoltaic systems is their lack of reliability. Depending on different solar irradiation levels and temperatures, their production rate varies. Therefore by adding a supplemental source of power, Solar Power's reliability can be greatly increased where this supplement energy source will work as a backup 
energy source. Whenever the load demand will not be fully met by the primary solar energy source it will be supported by the backup energy source. And on the other hand when the demand will be less than the generation, the primary solar source will energize the backup source.

\section{PV MODEL}

Figure 1 presents the widely used single-diode equivalent circuit model to represent the characteristics of the PV panel for analyzing and simulating the PV system. The circuit model represents the PV panel as a current source $\mathrm{I}_{\mathrm{ph}}$ in parallel with a single diode and a shunt resistor $\mathrm{R}_{\mathrm{P}}$ as well as a series resistor $\mathrm{R}_{\mathrm{S}}$. The current $\mathrm{I}_{\mathrm{PV}}$ and voltage $\mathrm{V}_{\mathrm{PV}}$ from the PV panel is characterized by the following Equations (1) and (2):

$$
\begin{gathered}
I_{P V}=I_{p h}-I_{D}-\frac{V_{P V}+R_{S} I_{P V}}{R_{S}} \\
I_{D}=I_{0}\left[\exp \left(\frac{q\left(V_{P V}+R_{S} I_{P V}\right)}{n A K T}\right)-1\right]
\end{gathered}
$$

where $I_{p h}$ is the current generated by the incident light, $I_{D}$ is the diode current, $I_{0}$ is the reverse saturation current, $\mathrm{q}$ is the electron charge $(1.602 \times 10-19 \mathrm{C}), \mathrm{K}$ is the Boltzmann constant $(1.38 \times 10-23 \mathrm{~J} / \mathrm{K}), \mathrm{T}$ is the operating temperature of the cell in Kelvin $(\mathrm{K}), \mathrm{A}$ is the diode ideality constant, and $n$ is the number of diodes in series to form the single-diode model. The current source Iph mainly depends on the irradiation level of sun light as well as the operation temperature of the solar panel.

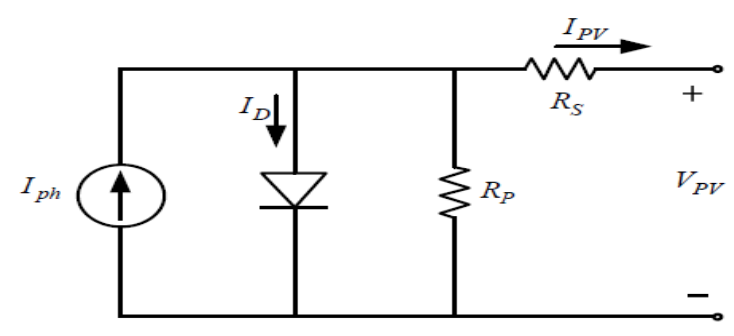

Fig. 1. Single-diode equivalent circuit model

In this study, the PV module was selected to conduct the design and circuit simulation; the table 1 present the $\mathrm{PV}$ model characteristics at $\left(25 \mathrm{C}^{\circ}\right.$ and $\left.1000 \mathrm{~W} / \mathrm{M}^{2}\right)$.

Table 1. The PV MODEL characteristics at ( $25 \mathrm{C}^{\circ}$ and $\left.1000 \mathrm{~W} / \mathrm{M}^{2}\right)$

\begin{tabular}{ll}
\hline Paramerter & Value \\
\hline Maximum Power & $\mathbf{6 1 . 2 4 ~ W}$ \\
Tension at Pmax & $\mathbf{1 7 . 3 2} \mathbf{~ V}$ \\
Current Pmax & $\mathbf{3 . 5} \mathbf{A}$ \\
Open circuit Voltage & $\mathbf{2 1 . 0 2 ~ V}$ \\
Short circuit Current & $\mathbf{3 . 8 \mathrm { A }}$ \\
\hline
\end{tabular}




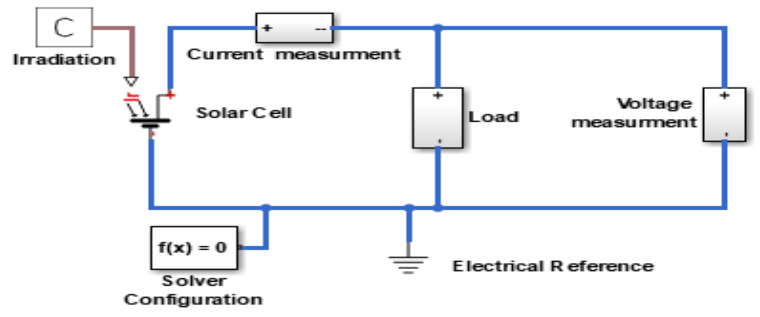

Fig. 2. PV Model Simulation

\subsection{Current -Voltage and Power-Voltage characteristics}

One way of studying the consistency of the model is developed to study the shape of the current-voltage characteristics I-V, Fig. 3 and P-V, power-voltage, Fig. 4, was obtained using the equations the electrical model (1) and (2)

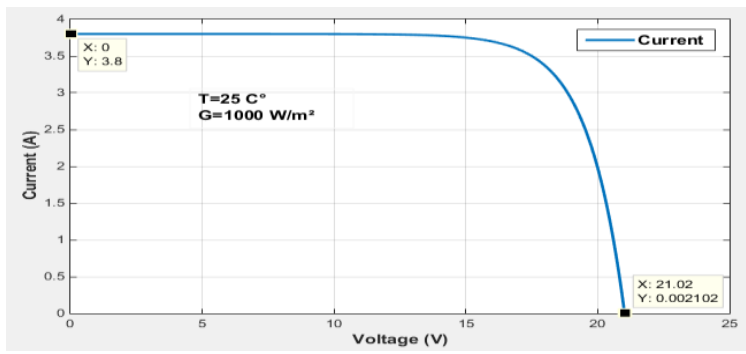

Fig. 3. Single diode equivalent circuit Model

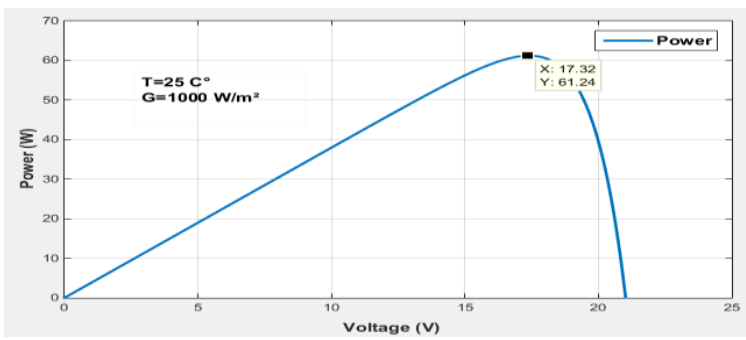

Fig. 4. P-V Characteristics curve of PV panel Simulation

\subsection{Influence of temperature}

To characterize PV cells, we used the model Fig.2, to provide the values of voltage, current product and the power generated. We present the $\mathrm{I}-\mathrm{V}$ and $\mathrm{P}-\mathrm{V}$ characteristics in figures 5 and 6 respectively of $\mathrm{PV}$ panel, for $\mathrm{G}=1000 \mathrm{~W} / \mathrm{m}^{2}$ given, and for different values of temperature. If the temperature of the photovoltaic panel increases, the open circuit voltage Voc decreases. The temperature increase is also reflected by the decrease of the maximum power. 


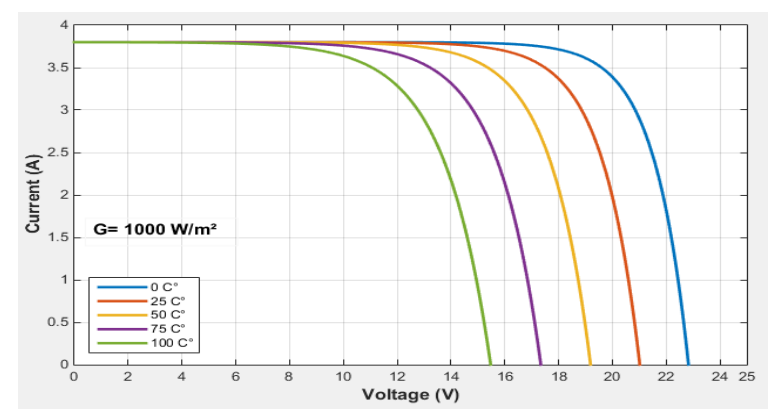

Fig. 5. Simulated I-V Curves of PV Model influenced by tepmerature

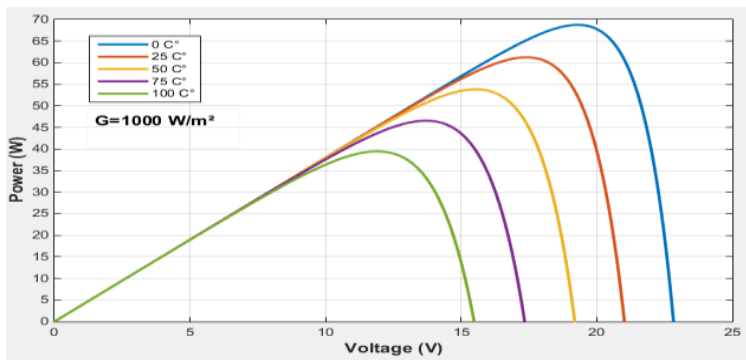

Fig. 6. Power versus Voltage P-V curves influenced by tempurature

\subsection{Influence of irradiation}

Now, we present the $\mathrm{I}-\mathrm{V}$ and $\mathrm{P}-\mathrm{V}$ characteristics in figures 7 and 8 respectively of the $\mathrm{PV}$ photovoltaic model at a given temperature $\mathrm{T}=25^{\circ} \mathrm{C}$ for different solar illumination levels.

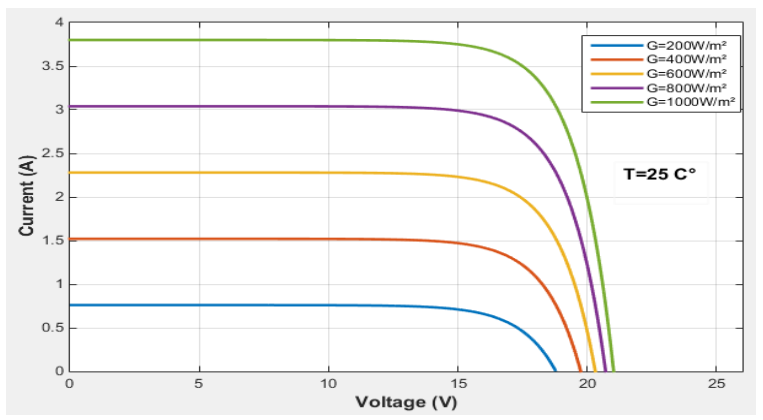

Fig.7.Simulated I-V curves of PV model influenced by solar illumination 


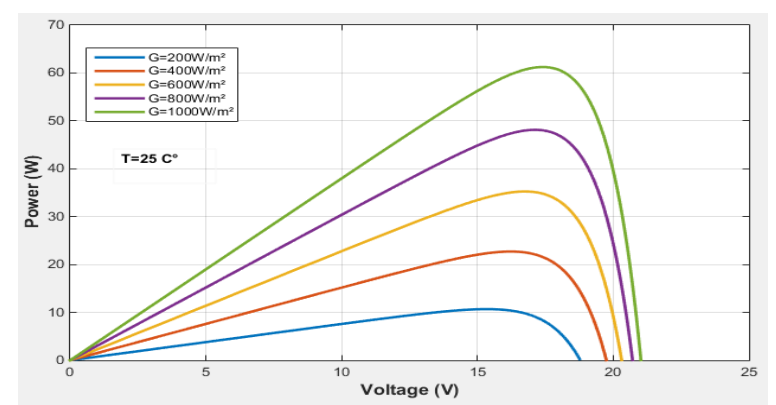

Fig. 8. Power versus voltage P-V curves influenced by solar illumination

\subsection{DC/DC boost converter}

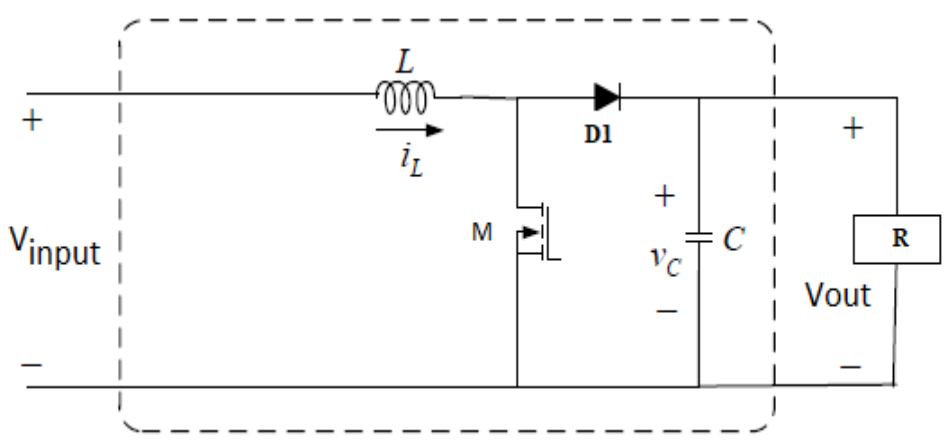

Fig.9. DC/DC boost converter

The boost DC/DC converter offers a greater level of capability, it as expected it extra components may be required to provide the level of functionality needed [3], [4], [5].

In Fig. 9 a DC/DC Boost converter is shown. The switching period is $T$ and the duty cycle is $D$. Assuming continuous conduction mode of operation, during $\mathrm{T}_{\mathrm{ON}}$ the period of the cycle, switch $\mathrm{M}$ is $O N$ and the input voltage is impressed across the inductor. Since the load current is instantaneously provided by the output capacitor during this interval, the capacitor voltage (output voltage) decreases, the state space equations are given by Eq.(3).

$$
\left\{\begin{array}{l}
\frac{d i_{L}}{d t}=\frac{1}{L}\left[v_{i n}\right] \\
\frac{d v_{C}}{d t}=-\frac{1}{c}\left(\frac{v_{c}}{R}\right)
\end{array}\right.
$$

During the other interval of the switching period $\left(\mathrm{T}_{\mathrm{OFF}}\right)$, Diode $\mathrm{D} 1$ is turned $O N$ and the inductor energy is transferred to the output, providing both the load current and also charging the output capacitor, the equations are given by Eq.(4). 


$$
\left\{\begin{array}{l}
\frac{d i_{L}}{d t}=\frac{1}{L}\left[v_{i n}-v_{c}\right] \\
\frac{d v_{c}}{d t}=\frac{1}{c}\left(i_{L}-\frac{v_{c}}{R}\right)
\end{array}\right.
$$

\subsection{MPPT Control algorithm}

The configuration of MPPT controller is shown in Fig.10. The inputs of MPPT controller are voltage and current of the PV model, while the output is PWM (pulse width modulation) for controlling the duty cycle of the boost converter. The system is simulated using Matlab/Simulink. Many MPPT techniques have been proposed in the literature; examples are the Perturb and Observe (P\&O), Incremental Conductance (IC), Fuzzy Logic, and so forth. The P\&O algorithm is very popular and simple [6], [7], [8], [9], [10].

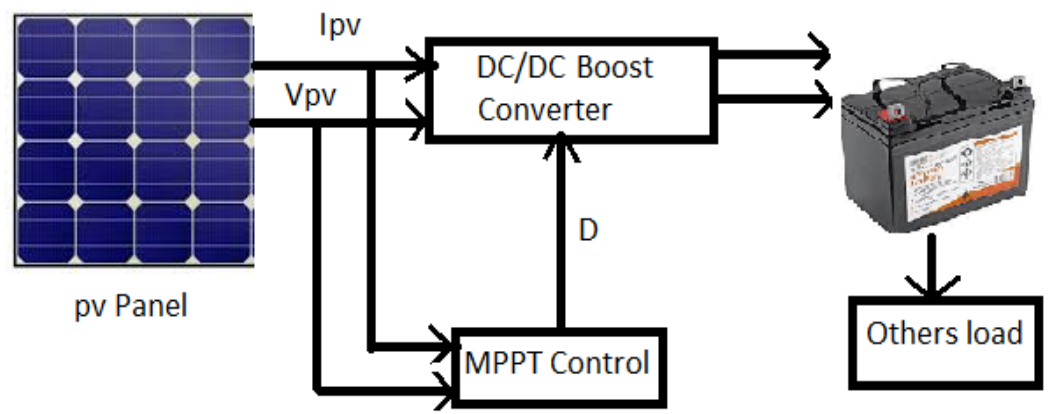

Fig.10. PV System with Power conveter and MPPT Control

\subsection{Incremental conductance method}

This method is based on the fact that the slope of the power curve of the panel is zero at the MPP, positive to the left and negative to right. This method is based on the fact that the slope of the power curve of the panel is zero at the MPP, positive to the left and negative to right [11], [12], [13], [14]. Since :

$$
\frac{d P}{d V}=\frac{d(I V)}{d V}=I+V \frac{d I}{d V}=I+V \frac{\Delta I}{\Delta V}
$$




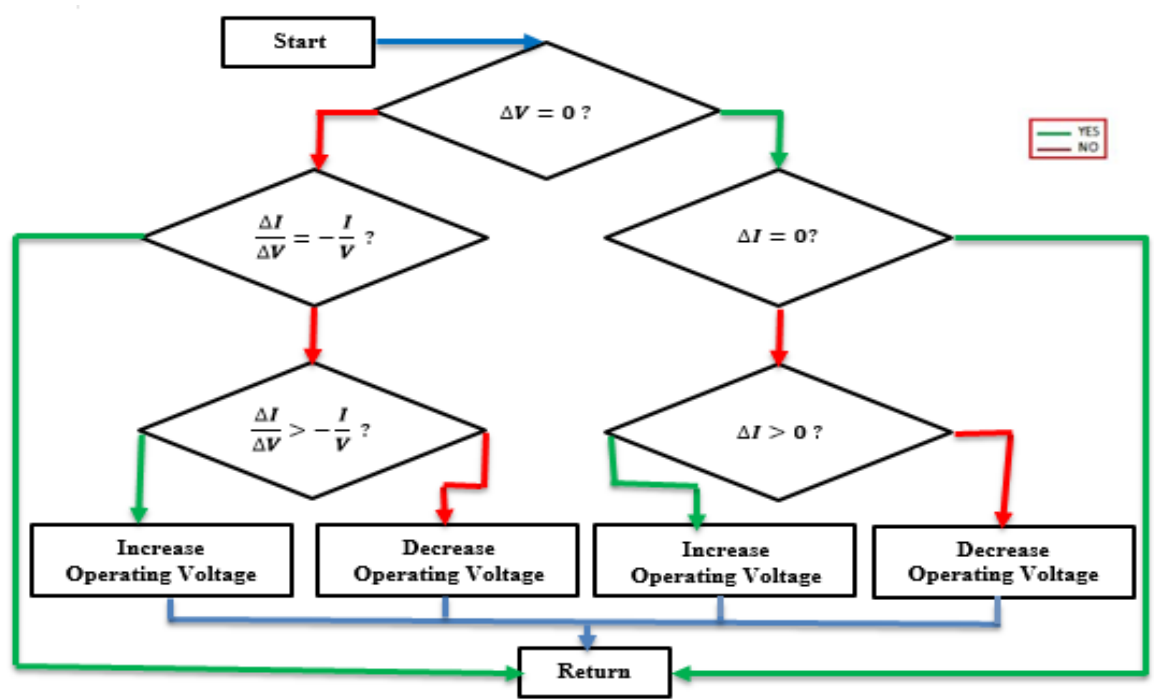

Fig.11.Organigram of incremental conductance algorithm

$$
\begin{cases}\frac{\Delta I}{\Delta V}=-\frac{I}{V} & \text { at the MPP } \\ \frac{\Delta I}{\Delta V}>-\frac{I}{V} & \text { left of the MPP } \\ \frac{\Delta I}{\Delta V}<-\frac{I}{V} & \text { right of the MPP }\end{cases}
$$

The MPP can be tracked by comparing the instantaneous conductance to the incremental conductance, as shown in the organogram of Fig.11. The detailed Simulink model is shown in Fig.12. The Vpv and Ipv are taken as the inputs to MPPT unit, duty D cycle is obtained as output.

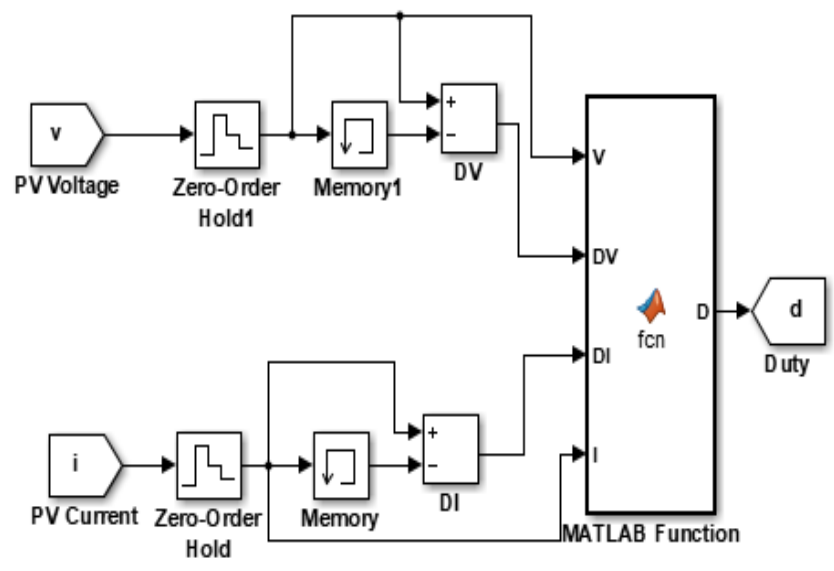

Fig.12. Maximum power point tracking by incremental conductance method 


\section{Simulation model of PV system with incremental conductance algorithm}

The model shown in Fig.13 represents a model of PV solar panel connected to resistive load through a DC/DC boost converter with Incremental Conductance Algorithm. The boost system specifications are given as follows:

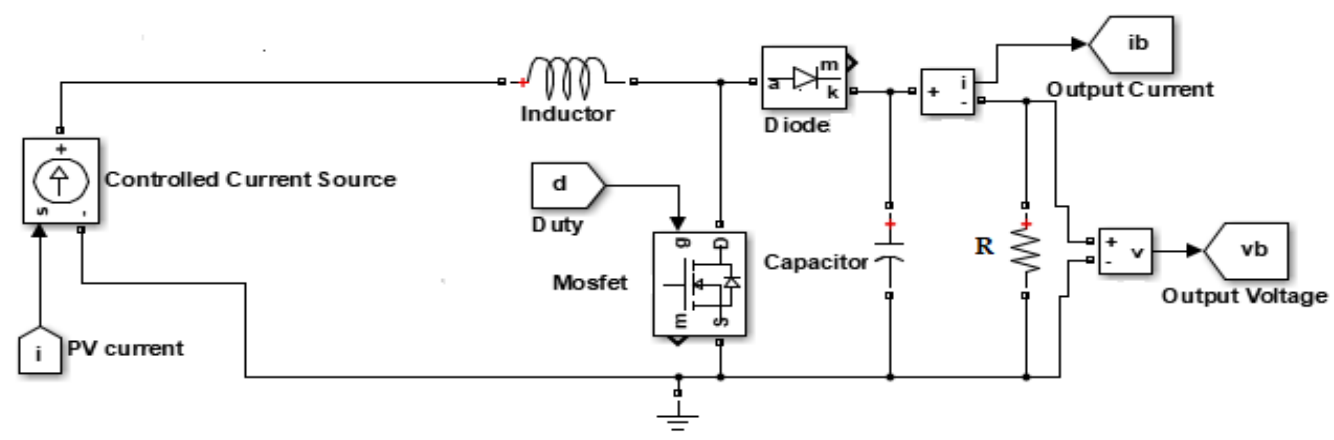

Fig.13 Boost converter circuit with PV input

Figure 14 presents how the irradiance that falls on PV solar panel is changing. The voltage and the current vary depending on irradiance. The curve of variable irradiance is plotted using a signal builder, where the irradiance is not very realistic, that will be equivalent to do very fast cloud moving for example, what allowing to the sun changing instantaneous which is not happen, but allow to give an idea of measure of how fast the controller responds [15].

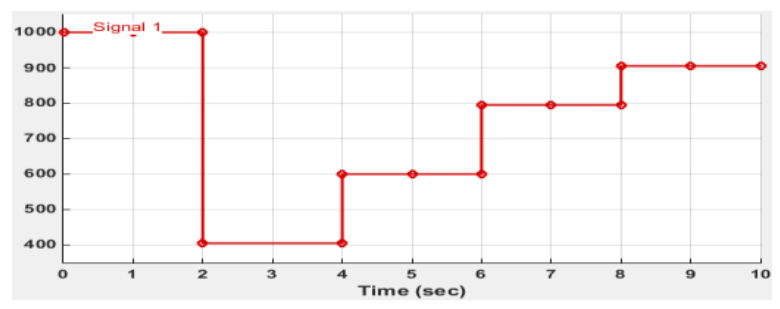

Fig.14. Variation of solar radiation

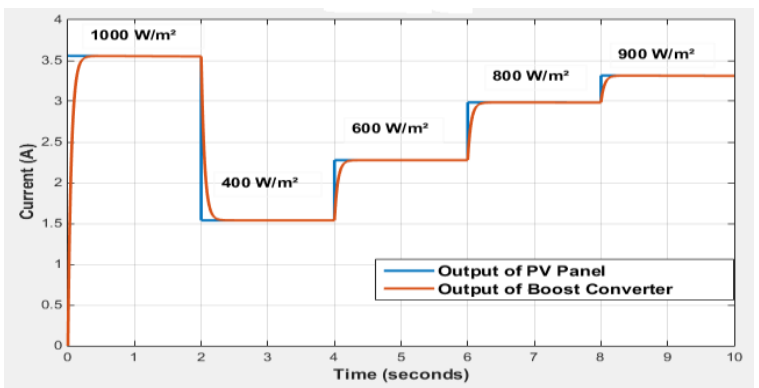

Fig.15. Output current of the Boost converter and output current of the PV panel 


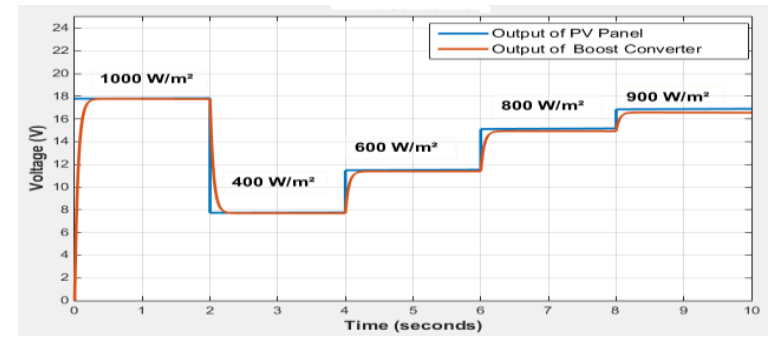

Fig.16. Output Voltage of the Boost converter and output Voltage of the PV panel

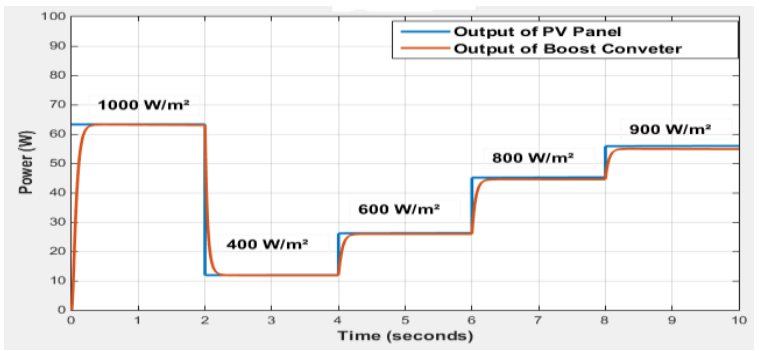

Fig.17. Output power of the Boost converter and output power of the PV panel

Figure 15 to 17 presents the results of the simulation model PV panel. The current, voltage and power output of PV panel and at the output of circuit connected to the photovoltaic panel. The Irradiance is variable, passing successively through the following values: 1000, 400, 600, 800 and $900 \mathrm{~W} / \mathrm{m}^{2}$. To test the operation of the system, the change of solar radiation was modeled. The temperature is fixed at $25{ }^{\circ} \mathrm{C}$ and the level of solar radiation is varied with five levels. The first level of illumination is set at $1000 \mathrm{~W} / \mathrm{m}^{2}$ then at 2 second the solar irradiation level passed abruptly at the second level $400 \mathrm{~W} / \mathrm{m}^{2}$, next at 4 second, it passed at the third level $600 \mathrm{~W} / \mathrm{m}^{2}$, after that at 6 second, it passed at the $800 \mathrm{~W} / \mathrm{m}^{2}$, Finally at 8 second, it passed at the last level $\mathrm{G}=900 \mathrm{~W} / \mathrm{m}^{2}$. An illustration of the relationship between the irradiation and the output power of PV panel is shown in figure 15 to 17 to explain the effectiveness of the algorithm mentioned. According to the simulation results presented above, all quantities to regulate, and converge well to references, and after a few time acceptable response $=0.1 \mathrm{~s}$ These results show the effectiveness of the algorithm and the relationship between the illumination and the output power of the PV panel, and show the operation of the boost converter.

\section{Conclusion}

In this paper, a standalone PV system has been simulated by Matlab/Simulink. Incremental conductance algorithm has been used for maximum power point tracking. Simulation results show that the system operates in the maximum power point. This technique has an advantage over the perturb and observe method because it can determine when you reach the MPP without having to oscillate around this value. It can also perform MPPT under rapidly increasing and decreasing irradiance conditions with higher accuracy than the perturb and observe method. 


\section{References}

[1] A. A bete, E .Barbis io, F.Cane, and P. Demartini, - Analysis of photovoltaic modules with protection diodes in presence of mismatching,, in Photovoltaic Specialists Conference, 1990., Conference Record of the Twenty First IEEE, pp. 1005-1010 vol. 2 (1990)

[2] Jie Shi ; Wei-Jen Lee ; Yongqian Liu ; Yongping Yang ; Wang, Peng \|Forecasting power output of photovoltaic system based on weather classification and support vector machinell Industry Applications Society Annual Meeting (IAS), 2011 IEEE DOI: 10.1109/IAS.2011.6074294 Publication Year: 2011 Y.T. Tan, D.S. Kirschen and N. Jenkins, 'A Model of PV Generation Suitable for Stability Analysis', IEEE Transactions on Energy Conversion, Vol. 19, N4, pp. $748-755,(2004)$.

[3] A. Brambilla, M. Gambarara, A. Garutti and F. Ronchi, 'New Approach to Photovoltaic Panels Maximum Power Point Tracking', 30th Annual IEEE Power Electronics Specialists Conference, PESC'99, Vol. 2, pp. 632 - 637, (1999).

[4] J.A. Gow and C.D. Manning, 'Development of a Photovoltaic Panel Model for Use in Power Electronics Simulation Studies', IEE Proceedings on Electric Power Applications, Vol. 146, N², pp. 193 - 200, March (1999).

[5] E. Solodovnik, S. Liu and R. Dougal, 'Power Controller Design for Maximum Power Tracking in Solar Installations', IEEE Transactions on Power Electronics, Vol. 19, N5, pp. 1295 - 1304, (2004).

[6] J.A. Gow and C.D. Manning, 'Development of a Photovoltaic Panel Model for Use in Power Electronics Simulation Studies', IEE Proceedings on Electric Power Applications, Vol. 146, N², pp. 193 , March.(2000)

[7] M. Nabipour, M. Razaz, S.GH Seifossadat, S.S. Mortazavi "A new MPPT scheme based on a novel fuzzy approach" Renewable and Sustainable Energy Reviews 74 (2017) 1147-1169-journal homepage: www.elsevier.com/locate/rser.(1999)

[8] Serkan Öztürka, Polat Poșpoşa, Volkan Utalayb, Atila Koçb, Muammer Ermişc, Işıı Çadırcıa,"Operating principles and practical design aspects of all SiC DC/AC/DC converter for MPPT in grid-connected PV supplies" Solar Energy 176 380-394.journal homepage: www.elsevier.com/locate/solener. (2018)

[9] Buvana Lefevrea, Bert Herteleera, Sven De Breuckerb, Johan Driesena "Bayesian inference based MPPT for dynamic irradiance conditions" Solar Energy 174 1153-1162, journal homepage: www.elsevier.com/locate/solener. (2018)

[10] A. Chermitti, O. Boukli-Hacene and S. Mouhadjer, 'Design of a Library of Components for Autonomous Photovoltaic System under Matlab/Simulink', International Journal of Computer Applications, (0975 - 8887), Vol. 53, N¹4, (2012).

[11] T.C. Yu and T.S. Chien, 'Analysis and Simulation of Characteristics and Maximum Power Point Tracking for Photovoltaic Systems', In Proceedings of the International Conference on Power electronics and Drive Systems (PEDS '09), pp. 1339 - 1344, January (2009).

[12] M.A.S. Masoum, H. Dehbonei and E.F. Fuchs, 'Theoretical and Experimental Analyses of Photovoltaic Systems With Voltage-and Current-Based Maximum Power-Point Tracking', IEEE Transactions of Energy Conversion, Vol. 17, $\mathrm{N}^{\circ} 4$, pp. $514-522,(2002)$

[13] F. Adamo, F. Attivissimo, A. Di Nisio and M. Spadavecchia, 'Characterization and Testing of A Tool for Photovoltaic Panel Modeling', IEEE Transactions on Instrumentation and Measurement, Vol. 60, №5, pp. 1613 - 1622, May (2011).

[14] I.H. Altas and A.M. Sharaf, 'A Photovoltaic Panel Simulation Model for Matlab-Simulink GUI Environment', International Conference on Clean Power, pp. 341 - 345, (2007). 